\title{
Turismo: o ensino de graduação no Brasil
}

\author{
Tourism: graduation in Brazil
}

\author{
Marlene Matias (MATIAS, M.) ${ }^{*}$
}

\begin{abstract}
RESUMO - O presente artigo tem por objetivo apresentar um panorama do ensino de graduação em turismo no Brasil, compreendendo: o ensino presencial de graduação em turismo e das denominadas áreas afins ao turismo e o ensino a distância de graduação em turismo e de áreas afins ao turismo. Para demonstrar esse panorama foram realizadas pesquisas em fontes secundárias como livros, anuários estatísticos e sites. Inicialmente apresentam-se as origens e a evolução dos cursos de graduação em turismo e das áreas afins ao turismo no país, e também se mostra o comportamento da atividade em termos de números de cursos, vagas oferecidas, candidatos inscritos no vestibular e em outros processos seletivos, ingressos e egressos. Posteriormente é apresentada uma análise do ensino de graduação das áreas afins ao turismo onde são apontadas suas relações e as possíveis interferências que estão provocando no ensino do turismo. Na sequência aborda-se o ensino a distância de turismo e áreas afins ao turismo. Nas considerações finais apresenta-se uma análise comparativa do ensino de graduação em turismo em relação ao ensino das áreas afins ao turismo.
\end{abstract}

Palavras-chave: Curso de Turismo; Ensino de Turismo; Áreas afins ao turismo; Ensino a distância.

ABSTRACT - This article intends to present an overview on tourism graduation in Brazil, comprising: the presential tourism graduation courses and its related areas, as well as distance tourism graduation courses and its related areas. To demonstrate this overview, it was accomplished researches in secondary sources such as: books, statistical yearbooks and websites. First of all it is presented the origins and evolution of tourism graduation courses and its related areas in Brazil, and it is also showed the behavior of the activity in terms of numbers of courses, places offered, candidates enrolled in vestibular and in other selection processes, beginners and seniors. So then it is showed an analysis about tourism related areas graduation where it is pointed their relations and the possible interferences en the tourism graduation courses. In the sequence it is discussed the distance tourism graduation courses and its related areas. In the final considerations it is presented a comparative analysis of tourism graduation in relation other related areas.

Key words: Tourism courses; Tourism graduation; Tourism related areas; Distance learning.

\footnotetext{
* Formação: Graduação em Turismo (Bacharelado) pela Faculdade Ibero-Americana de Letras e Ciências Humanas. Mestrado em Ciências da Comunicação pela Escola de Comunicação e Artes da Universidade de São Paulo (ECA/USP). Doutoranda do Programa de Ciências Sociais da Pontifícia Universidade Católica de São Paulo (PUCSP). Professora do curso de Turismo da PUCSP; e consultora da área de turismo. Endereço para correspondência: Rua Lisboa 433, ap. 72 (Bairro Cerqueira Cesar). CEP: 05413000 - São Paulo - SP (Brasil). E-mail: marmatias@uol.com.br.
} 


\section{INTRODUÇÃO}

Este trabalho tem por objetivo apresentar as origens e a evolução do ensino superior de Turismo e também das denominadas Áreas Afins ao Turismo no ensino presencial, como também sobre o surgimento do ensino a distância de graduação em Turismo e das Áreas Afins ao Turismo. A sua elaboração baseou-se em pesquisa bibliográfica, realizada em fontes secundárias como: livros, anuários estatísticos e em sites.

Inicialmente será apresentado um panorama do ensino de graduação presencial em Turismo, no país, desde a sua origem, em 1971 até o ano 2009, e também se mostra o comportamento da atividade em termos de número de cursos, vagas oferecidas, candidatos inscritos no vestibular e em outros processos seletivos, ingressos e concluintes.

Posteriormente é apresentada uma análise do ensino de graduação das Áreas Afins ao Turismo, onde são apontadas suas relações e as possíveis interferências que estão provocando no ensino do Turismo.

Na sequência será mostrado como se encontra o Ensino a Distância de Turismo e também das Áreas Afins ao Turismo.

Nas considerações finais é realizada uma análise comparativa do ensino de graduação em Turismo em relação ao ensino das Áreas Afins ao Turismo, e também será mencionado sobre o que pode representar o Ensino a Distância nesse contexto.

\section{O ENSINO DE GRAdUAÇÃO PRESENCIAL E A DistânCIA EM TURISMO E DAS ÁREAS AFINS NO BRASIL}

Inicialmente tratar-se-á neste tópico das origens e evolução dos cursos de graduação em Turismo, onde será apresentado o seu surgimento e depois a sua evolução em termos de crescimento ao longo dos anos visando atender às necessidades do setor de Turismo, carente de mão de obra qualificada. Posteriormente será abordado o surgimento e evolução dos cursos de graduação das denominadas Áreas Afins ao Turismo, que sinalizam uma nova tendência do ensino do Turismo voltada mais para a 
especialização em determinada área do saber, do que uma formação generalista que predominou até o final dos anos de 1990.

Para finalizar são comentados também os passos iniciais da Educação a Distância em Turismo e também das denominadas Áreas Afins ao Turismo.

\subsection{CURSOS DE GRADUAÇÃO PRESENCIAL EM TURISMO: ORIGENS, EVOLUÇÃO E TENDÊNCIAS.}

O ensino do Turismo em países da Europa e nos Estados Unidos é ministrado na forma de uma disciplina em outros cursos como: Administração, Economia, Geografia e outros.

No Brasil o ensino do Turismo foi instituído pelo Ministério da Educação MEC com a publicação do Parecer CFE $\mathrm{n}^{\circ}$. 35/71, que criou o curso superior de Turismo e da Resolução S./N., de 28 de janeiro de 1971, que fixou o currículo mínimo e a duração do curso de Turismo.

O primeiro curso de Turismo implantado no país foi o - da Faculdade Anhembi Morumbi, atual Universidade Anhembi Morumbi - em 1971 e que recebeu reconhecimento legal após a formação da sua primeira turma em 1974.

$\mathrm{O}$ ensino superior do Turismo no Brasil surgiu no momento em que o ensino superior passava por modificações, isto é, buscava-se dar à formação educacional um caráter profissionalizante para atender as necessidades do mercado, o qual demandava por profissionais treinados para desempenhar funções de produção em série padronizada.

Isso fez com que o curso de Turismo, já na sua criação sofresse algumas críticas e preconceitos por parte de dirigentes das outras áreas do conhecimento, que acreditavam que o graduado em curso superior de Turismo seria apenas um "tarefeiro", sem nenhuma base de conhecimento para desenvolver qualquer trabalho que exigisse reflexão. Essa visão preconceituosa em relação ao curso de Turismo ainda persiste nos meios acadêmicos e empresariais, prejudicando o ensino do Turismo e a formação profissional. 
Nos anos de 1970 segundo Trigo (2000, p. 213-219) existiam 20 cursos superiores de Turismo. Na década de 1980 foram criados outros 5 cursos de Turismo o que representou um crescimento de $25 \%$, em relação ao período anterior.

A evolução do número de cursos de 1971 a 1990 destinados ao ensino de graduação em Turismo no país pode ser constatada no Quadro 1 a seguir, onde se pode observar que nos anos de 1972, 1979, 1982, 1983, 1986, 1988, 1989 e 1990 não houve abertura de novos cursos.

\begin{tabular}{|c|c|}
\hline ANO & CRIAÇÃO DE CURSOS DE TURISMO \\
\hline 1971 & 1 \\
\hline 1972 & 0 \\
\hline 1973 & 8 \\
\hline 1974 & 2 \\
\hline 1975 & 1 \\
\hline 1976 & 4 \\
\hline 1977 & 1 \\
\hline 1978 & 1 \\
\hline 1979 & 0 \\
\hline 1980 & 2 \\
\hline 1981 & 1 \\
\hline 1982 & 0 \\
\hline 1983 & 0 \\
\hline 1984 & 1 \\
\hline 1985 & 2 \\
\hline 1986 & 0 \\
\hline 1987 & 1 \\
\hline 1988 & 0 \\
\hline 1989 & 0 \\
\hline 1990 & 0 \\
\hline TOTAL & 25 \\
\hline
\end{tabular}

QUADRO 1 - EVOLUÇÃO DA CRIAÇÃO DOS CURSOS DE TURISMO, NO PERÍODO DE 1971 A 1990.

QUADRO ELABORADO POR: MARLENE MATIAS

FONTES: TRIGO $(1991 ; 2000)$ E REJOWSKI (1996).

Na década de 1990, após o governo de Fernando Collor de Melo, a atividade turística voltou a crescer, isto é, a entrada de turistas estrangeiros no país volta a aumentar, conforme mostra o Quadro 2 a seguir.

Esse reaquecimento da atividade turística no país reafirma a sua importância econômico-social como geradora de emprego e renda, o que desperta nas instituições de ensino o interesse pela implantação de cursos superiores de Turismo, visando atender as necessidades do setor. 


\begin{tabular}{|c|c|}
\hline ANO & NÚMERO DE TURISTAS 1 \\
\hline 1980 & 1.625 .422 \\
\hline 1981 & 1.357 .879 \\
\hline 1982 & 1.146 .681 \\
\hline 1983 & 1.420 .481 \\
\hline 1984 & 1.595 .726 \\
\hline 1985 & 1.753 .982 \\
\hline 1986 & 1.934 .091 \\
\hline 1987 & 1.929 .053 \\
\hline 1988 & 1.742 .939 \\
\hline 1989 & 1.402 .897 \\
\hline 1990 & 1.091 .067 \\
\hline 1991 & 1.228 .172 \\
\hline 1992 & 1.692 .078 \\
\hline 1993 & 1.641 .138 \\
\hline 1994 & 1.853 .301 \\
\hline 1995 & 1.991 .416 \\
\hline 1996 & 2.665 .508 \\
\hline 1997 & 2.849 .750 \\
\hline 1998 & 4.818 .084 \\
\hline 1999 & 5.107 .169 \\
\hline 2000 & 5.313 .463 \\
\hline 2001 & 4.772 .575 \\
\hline 2002 & 3.784 .898 \\
\hline 2003 & 4.132 .847 \\
\hline 2004 & 4.793 .703 \\
\hline 2005 & 5.358 .170 \\
\hline 2006 & 5.017 .251 \\
\hline 2007 & 5.025 .834 \\
\hline 2008 & 5.050 .099 \\
\hline 2009 & 4.802 .217 \\
\hline 2010 & 5.161 .379 \\
\hline
\end{tabular}

QUADRO 2 - ENTRADA DE TURISTAS ESTRANGEIROS NO BRASIL (EM MILHÕES).

FONTE: BRASIL. MTUR/EMBRATUR - MINISTÉRIO DO TURISMO. ANUÁRIO ESTATÍSTICO 2011.

Mesmo não possuindo dados detalhados sobre a oferta de cursos de Turismo no período de 1990 a 1994, segundo as pesquisadoras Ansarah e Rejowski (1996, p. 38) nesse período o país possuía 49 cursos de Turismo e Hotelaria, o que demonstra que a oferta cresceu $68,9 \%$ em relação à década de 1980.

Outro fato que mostra essa tendência de crescimento a partir da década de 1990 pode ser constado no Quadro 3 abaixo, que apresenta dados da Sinopse Estatística e Microdados do Censo da Educação Superior ${ }^{1}$, que passou a ser realizado a partir de

\footnotetext{
${ }^{1}$ O Censo da Educação Superior - é o principal instrumento de coleta de informações sobre a educação superior no Brasil, a Sinopse de dados Estatísticos e Microdados do Censo da Educação Superior é elaborada a partir de dados obtidos pelo Censo da Educação Superior.
} 
1995, pelo MEC, Instituto Nacional de Estudos e Pesquisas Educacionais Anísio

Teixeira - INEP e Diretoria de Estatísticas Educacionais - DEED.

\begin{tabular}{|c|c|c|c|c|c|c|c|c|c|c|c|c|c|c|c|}
\hline \multirow{2}{*}{$\begin{array}{l}\text { ORGANIZAÇÃO } \\
\text { ACADÊMICA } \\
\text { ADMINISTRATIVA }\end{array}$} & \multicolumn{15}{|c|}{ ANOS } \\
\hline & 1995 & 1996 & 1997 & $1998^{1}$ & 1999 & $2000^{2}$ & 2001 & 2002 & 2003 & $2004^{3}$ & 2005 & 2006 & 2007 & $2008 *$ & 2009 \\
\hline UNIVERSIDADES & 18 & 21 & 31 & 44 & 60 & 83 & 99 & 107 & 119 & 125 & 131 & 134 & 155 & 148 & 116 \\
\hline$\bullet \quad$ Federal & 3 & 4 & 5 & 6 & 6 & 10 & 10 & 11 & 14 & 15 & 15 & 20 & 22 & 22 & 23 \\
\hline Estadual & 2 & 2 & 2 & 3 & 3 & 6 & 6 & 9 & 11 & 12 & 12 & 16 & 16 & 19 & 20 \\
\hline - $\quad$ Municipal & 1 & 1 & 1 & 2 & 1 & - & - & 1 & 3 & 3 & 3 & 3 & 4 & 4 & 0 \\
\hline - $\quad$ Particular & 12 & 14 & 23 & 33 & 50 & 67 & 83 & 86 & 91 & 95 & 101 & 95 & 113 & 103 & 73 \\
\hline CENTROS UNIVERSITÁRIOS & - & - & - & - & - & 32 & 40 & 42 & 44 & 61 & 69 & 65 & 71 & 68 & 47 \\
\hline$\bullet \quad$ Federal & - & - & - & - & - & - & - & - & - & - & - & - & - & - & - \\
\hline - $\quad$ Estadual & - & - & - & - & - & - & - & - & - & - & - & - & - & - & - \\
\hline Municipal & - & - & - & - & - & - & - & - & - & - & - & - & - & - & 1 \\
\hline - $\quad$ Particular & - & - & - & - & - & 32 & 40 & 42 & 44 & 61 & 69 & 65 & 71 & 68 & 46 \\
\hline FACULDADES INTEGRADAS & 9 & 10 & 8 & 17 & 12 & 18 & 23 & 27 & 34 & 32 & 29 & 28 & 31 & - & - \\
\hline$\bullet \quad$ Federal & - & - & - & - & - & - & - & - & - & - & - & - & - & - & - \\
\hline - $\quad$ Estadual & - & - & - & - & - & - & - & - & - & - & - & - & - & - & - \\
\hline - $\quad$ Municipal & - & - & - & - & 1 & 1 & 1 & 1 & 1 & 1 & 1 & 1 & 1 & - & - \\
\hline$\bullet \quad$ Particular & 9 & 10 & 8 & 17 & 11 & 17 & 22 & 26 & 33 & 31 & 28 & 27 & 30 & - & - \\
\hline FACULDADES ISOLADAS & 9 & 11 & 14 & 20 & 39 & - & - & - & - & - & - & - & - & - & - \\
\hline$\bullet \quad$ Federal & - & - & - & - & - & - & - & - & - & - & - & - & - & - & - \\
\hline - $\quad$ Estadual & - & - & - & - & - & - & - & - & - & - & - & - & - & - & - \\
\hline - $\quad$ Municipal & - & - & - & - & - & - & - & - & - & - & - & - & - & - & - \\
\hline • $\quad$ Particular & 9 & 11 & 14 & 20 & 39 & - & - & - & - & - & - & - & - & - & - \\
\hline $\begin{array}{l}\text { FACULDADES, ESCOLAS E } \\
\text { INSTITUTOS. }\end{array}$ & - & - & - & - & - & 76 & 139 & 196 & 227 & 236 & 237 & 249 & 250 & - & - \\
\hline • $\quad$ Federal & - & - & - & - & - & - & - & - & - & - & - & - & - & - & - \\
\hline - $\quad$ Estadual & - & - & - & - & - & 1 & 1 & 2 & 2 & 2 & 2 & 2 & 2 & - & - \\
\hline - $\quad$ Municipal & - & - & - & - & - & 1 & 1 & 1 & 1 & 2 & 3 & 3 & 2 & - & - \\
\hline • Particular & - & - & - & - & - & 74 & 137 & 193 & 224 & 232 & 232 & 244 & 246 & - & - \\
\hline FACULDADES & - & - & - & - & - & - & - & - & - & - & - & - & - & 277 & 179 \\
\hline • $\quad$ Federal & - & - & - & - & - & - & - & - & - & - & - & - & - & - & - \\
\hline - $\quad$ Estadual & - & - & - & - & - & - & - & - & - & - & - & - & - & 2 & 2 \\
\hline - $\quad$ Municipal & - & - & - & - & - & - & - & - & - & - & - & - & - & 3 & 4 \\
\hline • $\quad$ Particular & - & - & - & - & - & - & - & - & - & - & - & - & - & 272 & 174 \\
\hline $\begin{array}{l}\text { CENTRO DE EDUCAÇÃO } \\
\text { TECNOLOGICA/FCULDADES } \\
\text { DE TECNOLOGIA - CET/FAT }\end{array}$ & - & - & - & - & - & - & 1 & 5 & 6 & 7 & 10 & 10 & 19 & 8 & 2 \\
\hline$\bullet \quad$ Federal & - & - & - & - & - & - & 1 & 2 & 2 & 3 & 3 & 3 & 10 & 8 & 2 \\
\hline - $\quad$ Estadual & - & - & - & - & - & - & - & - & - & - & - & - & - & - & - \\
\hline - $\quad$ Municipal & - & - & - & - & - & - & - & - & - & - & - & - & - & - & - \\
\hline$\bullet \quad$ Particular & - & - & - & - & - & - & - & 3 & 4 & 4 & 7 & 7 & 9 & - & - \\
\hline TOTAL & 36 & 42 & 53 & 81 & 102 & 283 & 302 & 377 & 430 & 461 & 476 & 486 & 526 & 501 & 344 \\
\hline
\end{tabular}

QUADRO 3 - NÚMERO DE CURSOS DE GRADUAÇÃO EM TURISMO NO BRASIL POR ORGANIZAÇÃO ACADÊMICA E ADMINISTRATIVA NO PERÍODO DE 1995 A 2009.

QUADRO ELABORADO POR: MARLENE MATIAS

FONTE: BRASIL. SINOPSE ESTATÍSTICA E MICRODADOS DO CENSO DA EDUCAÇÃO SUPERIOR/MEC/INEP/DEED DE 1995 A 2009.

NOTAS:

(1) Os Centros Universitários foram computados junto com as Faculdades Integradas.

(2) Os Centros Universitários foram desmembrados das Faculdades Integradas e a terminologia Faculdades Isoladas é suprimida e passam a ser utilizados os termos Faculdades, Escolas e Institutos.

(3) Às Faculdades de Tecnologia foram agregados os Centros de Educação Tecnológica.

(*) As terminologias Faculdades Integradas e Faculdades, Escolas e Institutos foram suprimidas, passando a ser utilizado o termo Faculdades. A Terminologia Centro de Educação Tecnológica e Faculdades de Tecnologia foi alterada para Centro Federal de Educação Tecnológica e Instituto Federal de Educação, Ciência e Tecnologia - CEFET/IFET.

O Gráfico 1 a seguir possibilita uma melhor visualização do crescimento da oferta dos cursos de graduação em Turismo no período de 1995 a 2009. 


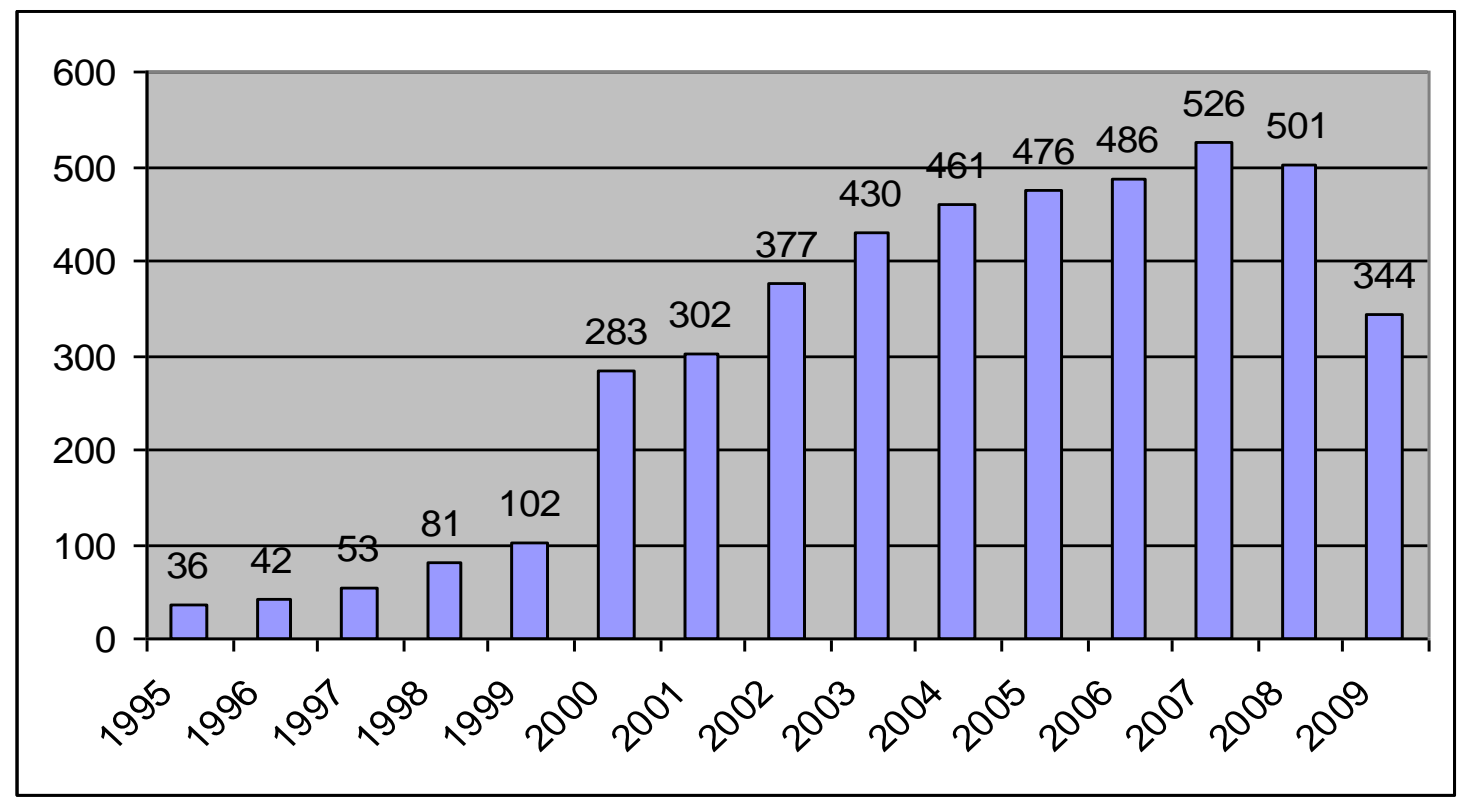

GRÁFICO 1 - NÚMERO DE CURSOS DE GRADUAÇÃO EM TURISMO NO BRASIL NO PERÍODO DE 1995 A 2009.

GRÁFICO ELABORADO POR: MARLENE MATIAS

FONTE: BRASIL. SINOPSE ESTATÍSTICA E MICRODADOS DO CENSO DA EDUCAÇÃO SUPERIOR/MEC/INEP/DEED DE 1995 A 2009.

Desde a criação do curso superior de Turismo houve crescimento moderado entre as décadas de 1970 (20 cursos) e 1980 (25 cursos), a partir da década de 1990 a oferta de cursos passou a aumentar, chegando a 283 cursos, isto é, 1032\% maior do que o período anterior.

Nos anos 2000 a oferta de cursos continuou a crescer, em 2007 atingiu um patamar de 526 cursos. Nesse ano algumas instituições que ofertavam curso de Turismo não obtiveram número suficiente de alunos inscritos e aprovados no vestibular para abrir novas turmas. A partir do ano de 2008 começa a ocorrer uma diminuição no número de cursos de Turismo ofertados conforme demonstrado no Gráfico 1 apresentado anteriormente.

A seguir o Gráfico 2 mostra a evolução dos cursos de Turismo no país desde sua criação até o ano de 2009. 


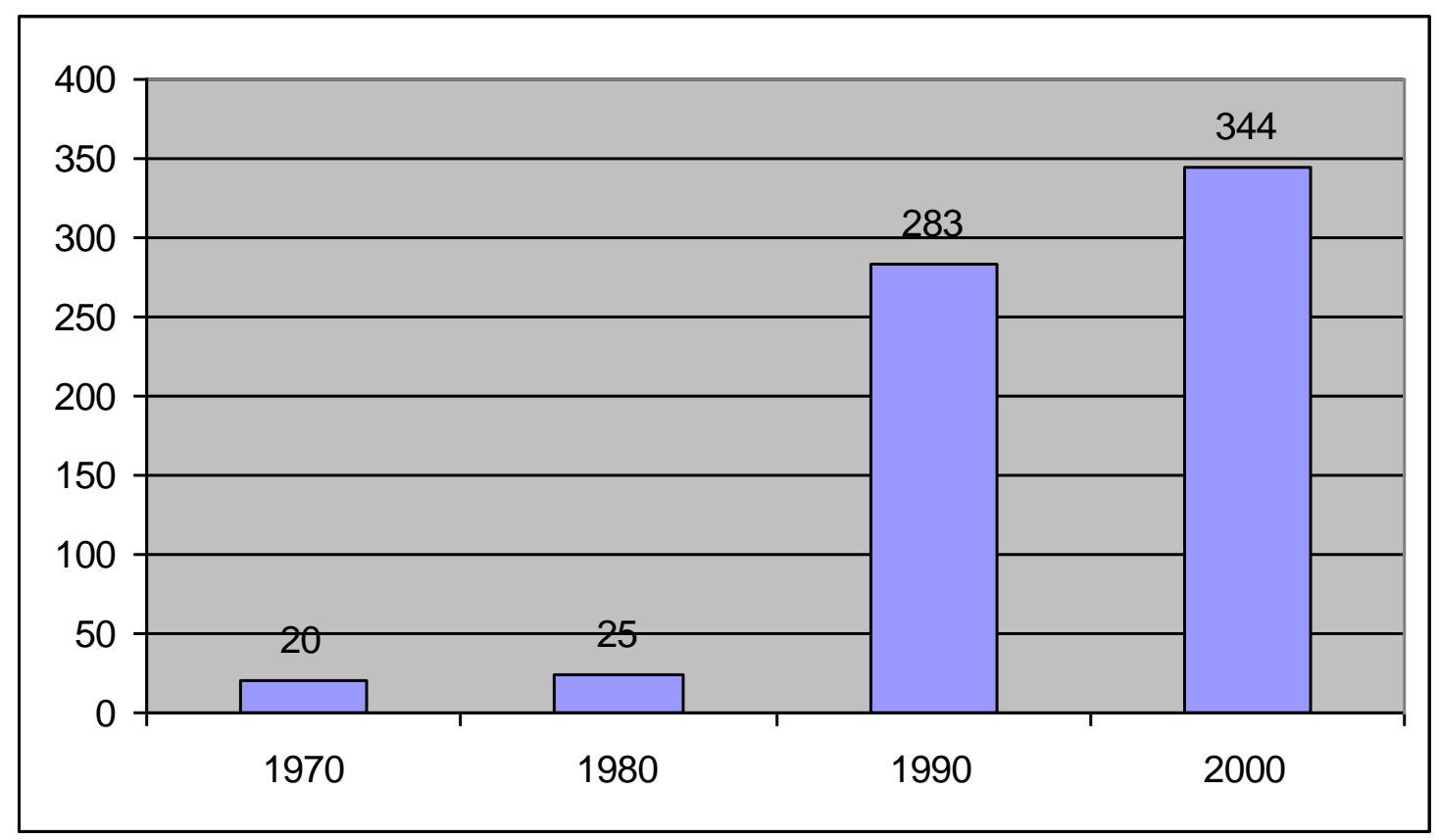

GRÁFICO 2 - EVOLUÇÃO DOS CURSOS DE GRADUAÇÃO EM TURISMO NAS DÉCADAS DE 1970, 1980, (E) 1990 E 2000 (INCOMPLETA ATÉ 2009).

GRÁFICO ELABORADO POR: MARLENE MATIAS.

FONTE: TRIGO (1991; 2000); REJOWSKI (1996) E SINOPSE ESTATÍSTICA E MICRODADOS DO CENSO DA EDUCAÇÃO SUPERIOR/MEC/INEP/DEED DE 1995 A 2009.

Outra tendência verificada também no período de 1995 a 2008 foi o aumento da oferta dos cursos de Turismo em instituições públicas, em nível Federal, Estadual e Municipal e nas instituições particulares até 2007. A partir de 2008 tanto as instituições publicas quanto as particulares apresentaram declínio nas suas ofertas de cursos, isto é, as ofertas nas instituições públicas diminuíram $11,2 \%$ e nas particulares $34 \%$.

O Quadro 4 abaixo apresenta a oferta de cursos de graduação em Turismo nas instituições públicas e particulares, onde se pode observar a tendência apresentada acima.

\begin{tabular}{|l|c|c|c|c|}
\hline \multirow{2}{*}{ ANO } & \multicolumn{4}{|c|}{ ORGANIZAÇÃO ADMINISTRATIVA } \\
\cline { 2 - 5 } & Federal & Estadual & Municipal & Particular \\
\hline 1995 & 3 & 2 & 1 & 30 \\
\hline 1996 & 4 & 2 & 1 & 35 \\
\hline 1997 & 5 & 5 & 2 & 45 \\
\hline 1998 & 6 & 3 & 2 & 91 \\
\hline 1999 & 6 & 3 & 2 & 264 \\
\hline 2000 & 10 & 7 & 2 & 282 \\
\hline 2001 & 11 & 7 & 3 & 350 \\
\hline 2002 & 13 & 11 & 5 & 396 \\
\hline 2003 & 16 & 13 & 6 & 423 \\
\hline 2004 & 18 & 14 & & \\
\hline
\end{tabular}

CONTINUA... 
CONTINUAÇÃO...

\begin{tabular}{|l|l|l|l|l|}
\hline 2005 & 18 & 14 & 7 & 437 \\
\hline 2006 & 23 & 18 & 7 & 438 \\
\hline 2007 & 32 & 18 & 7 & 469 \\
\hline 2008 & 30 & 21 & 5 & 443 \\
\hline 2009 & 25 & 22 & 292 \\
\hline
\end{tabular}

QUADRO 4 - CURSOS DE GRADUAÇÃO EM TURISMO POR ORGANIZAÇÃO ADMINISTRATIVA NO PERÍODO DE 1995 A 2009.

QUADRO ELABORADO POR: MARLENE MATIAS.

FONTE: FONTE: SINOPSE ESTATÍSTICA E MICRODADOS DO CENSO DA EDUCAÇÃO SUPERIOR/MEC/INEP/DEED DE 1995 A 2009.

Em 2009, a oferta de cursos de Turismo no país nas instituições públicas representava $15,2 \%$ enquanto as instituições particulares detinham $84,8 \%$ dessa oferta.

Outros dados que foram levantados e analisados para entender a dinâmica do ensino do turismo no país referem-se ao número de vagas, candidatos inscritos no vestibular, ingressos por vestibular e outros processos seletivos e também o número de concluintes que o mercado de trabalho recebe anualmente.

Os números de vagas ofertadas no período de 1995 a 2009 apresentaram índices de crescimento elevados entre os anos de 1997 a 2000, onde atingiu seu ápice 76,9\%. Após esse período sua evolução passou a oscilar, apresentando período de crescimento e de decréscimo a partir do ano de 2005, conforme mostra o Quadro 5 a seguir.

Analisando os dados referentes às vagas oferecidas em relação aos números de ingressos percebe-se que sempre a oferta de vagas foi maior do que o número de ingressos. $\mathrm{O}$ aumento do não preenchimento das vagas ofertadas começa a se tornar preocupante a partir do ano 2000 quando foram oferecidas 28.098 vagas e ocorreram 19.011 ingressos, o que significou 32,3\% de vagas não preenchidas, a partir de então esse percentual foi aumentando anualmente, passando dos 50\% em 2003 chegando a $79,0 \%$ em 2009.

\begin{tabular}{|c|c|c|c|c|c|c|c|}
\hline ANO & $\begin{array}{c}\text { NÚMERO DE } \\
\text { VAGAS } \\
\text { OFERECIDAS }\end{array}$ & $\begin{array}{c}\text { \% DE } \\
\text { VARIAÇÃO } \\
\text { DE } \\
\text { VAGA/ANO }\end{array}$ & $\begin{array}{c}\text { CANDIDATOS } \\
\text { INSCRITOS }\end{array}$ & $\begin{array}{c}\text { \% DE VARIAÇÃO } \\
\text { CANDIDATO } \\
\text { INSCRITO/ANO }\end{array}$ & INGRESSOS & $\begin{array}{c}\text { \% DE VARIAÇÃO } \\
\text { INGRESSO/ANO }\end{array}$ & $\begin{array}{c}\text { \% DE VAGAS } \\
\text { NÃO } \\
\text { PREENCHIDAS }\end{array}$ \\
\hline 1995 & 3.886 & $(-)$ & 6.823 & $(-)$ & 2.597 & $(-)$ & 33,1 \\
\hline 1996 & 4.301 & 10,6 & 13.209 & 93,5 & 3.628 & 39,6 & 15,6 \\
\hline 1997 & 6.686 & 55,4 & 20.460 & 54,8 & 5.447 & 50,1 & 18,5 \\
\hline 1998 & 9.931 & 48,5 & 23.206 & 13,4 & 8.702 & 59,7 & 12,3 \\
\hline 1999 & 15.880 & 59,8 & 41.734 & 79,8 & 13.337 & 53,2 & 16,0 \\
\hline 2000 & 28.098 & 76,9 & 63.680 & 52,5 & 19.011 & 42,5 & 32,3 \\
\hline
\end{tabular}


CONTINUAÇÃO...

\begin{tabular}{|l|l|c|c|c|c|c|c|}
\hline 2001 & 38.383 & 36,6 & 68.353 & 7,3 & 25.299 & 33,0 & 33,2 \\
\hline 2002 & 49.572 & 29,1 & 78.678 & 15,1 & 25.636 & 1,3 & 48,2 \\
\hline 2003 & 55.735 & 12,4 & 79.808 & 1,4 & 24.441 & $-3,3$ & 56,1 \\
\hline 2004 & 59.137 & 6,1 & 81.995 & 2,7 & 20.864 & $-14,4$ & 64,7 \\
\hline 2005 & 50.352 & $-14,8$ & 59.683 & $-27,2$ & 17.050 & $-18,2$ & 66,1 \\
\hline 2006 & 53.322 & 5,8 & 58.125 & $-2,6$ & 15.074 & $-11,5$ & 71,7 \\
\hline 2007 & 51.123 & $-4,1$ & 50.297 & $-13,4$ & 13.557 & $-10,0$ & 73,4 \\
\hline 2008 & 46.586 & $-8,8$ & 50.443 & 0,2 & 11.380 & $-16,0$ & 75,5 \\
\hline 2009 & 34.343 & $-26,2$ & 30.085 & $-40,3$ & 7.209 & $-36,6$ & 79,0 \\
\hline
\end{tabular}

QUADRO 5 - NÚMERO DE VAGAS, PERCENTUAL DE VARIAÇÃO ANUAL DE VAGAS, INGRESSOS POR VESTIBULAR E OUTROS PROCESSOS SELETIVOS, PERCENTUAL DE VARIAÇÃO DE INGRESSO E PERCENTUAL DE VAGAS NÃO PREENCHIDAS EM RELAÇÃO AO NÚMERO DE VAGAS OFERECIDAS NOS CURSOS DE GRADUAÇÃO EM TURISMO NO PERÍODO DE 1995 A 2009.

QUADRO ELABORADO POR: MARLENE MATIAS.

FONTE: SINOPSE ESTATÍSITCA E MICRODADOS DO CENSO DA EDUCAÇÃO SUPERIOR/MEC/INEP/DEED DE 1995 A 2009.

NOTA: (-) DADO NÃO DISPONÍVEL.

A seguir no Quadro 6 é apresentado um resumo com dados sobre oferta de cursos, vagas, candidatos inscritos, ingressos e concluintes somente por organização acadêmica. Não será mostrado por organização administrativa, porque a Sinopse Estatística e Microdados do Censo da Educação Superior possui essa informação somente do período de 1995 a 1999, deixando de apresentá-la partir do ano 2000. Todos esses itens foram considerados nas análises apresentadas acima que demonstram as tendências de crescimento do ensino do Turismo no país, principalmente, após o Governo de Fernando Collor de Melo. Na década de 1990 existiam no país 283 cursos de Turismo, se, for feita uma comparação com o período anterior houve um crescimento de $1032 \%$, nível esse não absorvido pelo mercado, causando o fechamento de cursos e a junção de instituições que tinham como principal fonte de recursos o curso o Turismo.

\begin{tabular}{|l|c|c|c|c|c|}
\hline \multicolumn{7}{|c|}{1995} \\
\hline ORGANIZAÇÃOO ACADEMICA & CURSOS & $\begin{array}{c}\text { VAGAS } \\
\text { OFERECIDAS }\end{array}$ & $\begin{array}{c}\text { CANDIDATOS } \\
\text { INSCRITOS }\end{array}$ & INGRESSOS & CONCLUINTES \\
\hline UNIVERSIDADES & 18 & 1.713 & 1.997 & 906 & 379 \\
\hline CENTROS UNIVERSITÁRIOS & - & - & - & - & - \\
\hline FACULDADES INTEGRADAS & 9 & 1.213 & 1.232 & 1.215 & 269 \\
\hline FACULDADES ISOLADAS & 9 & 960 & 3.594 & 985 & 175 \\
\hline $\begin{array}{l}\text { FACULDADES, ESCOLAS E } \\
\text { INSTITUTOS. }\end{array}$ & - & - & - & - & - \\
\hline $\begin{array}{l}\text { CENTRO DE EDUCAÇÃO } \\
\text { TECNOLOGICA }\end{array}$ & - & - & - & - & - \\
\hline TOTAL & $\mathbf{3 6}$ & $\mathbf{3 . 8 8 6}$ & $\mathbf{6 . 8 2 3}$ & $\mathbf{2 . 5 9 7}$ & $\mathbf{8 2 3}$ \\
\hline
\end{tabular}


CONTINUAÇÃO...

\begin{tabular}{|c|c|c|c|c|c|}
\hline \multicolumn{6}{|c|}{1996} \\
\hline UNIVERSIDADES & 21 & 1.886 & 6.608 & 1.504 & 432 \\
\hline -CENTROS UNIVERSITÁRIOS & - & - & - & - & - \\
\hline FACULDADES INTEGRADAS & 10 & 1.215 & 2.545 & 976 & 186 \\
\hline FACULDADES ISOLADAS & 11 & 1.200 & 4.056 & 1.148 & 260 \\
\hline $\begin{array}{l}\text { FACULDADES, ESCOLAS } \\
\text { INSTITUTOS. }\end{array}$ & - & - & - & - & - \\
\hline $\begin{array}{lrl}\text { CENTRO DE } & \text { EDUCAÇÃO } \\
\text { TECNOLOGICA } & \\
\end{array}$ & - & - & - & - & - \\
\hline TOTAL & 42 & 4.301 & 13.209 & 3.628 & 878 \\
\hline \multicolumn{6}{|c|}{1997} \\
\hline UNIVERSIDADES & 31 & 3.853 & 12.641 & 2.887 & 559 \\
\hline CENTROS UNIVERSITÁRIOS/ & - & - & - & - & - \\
\hline FACULDADES INTEGRADAS & 17 & 1.041 & 2.287 & 800 & 184 \\
\hline FACULDADES ISOLADAS & 14 & 1.792 & 5.532 & 1.760 & 180 \\
\hline $\begin{array}{lll}\text { FACULDADES, } & \text { ESCOLAS } & \text { E } \\
\text { INSTITUTOS. } & & \\
\end{array}$ & - & - & - & - & - \\
\hline $\begin{array}{lcc}\text { CENTRO DE } & \text { EDUCAÇÃO } \\
\text { TECNOLOGICA } & \\
\end{array}$ & - & - & - & - & - \\
\hline TOTAL & 53 & 6.686 & 20.460 & 5.447 & 923 \\
\hline \multicolumn{6}{|c|}{1998} \\
\hline UNIVERSIDADES & 44 & 6.277 & 15.887 & 5.686 & 626 \\
\hline CENTROS UNIVERSITÁRIOS/ & - & - & - & - & 310 \\
\hline FACULDADES INTEGRADAS & 17 & 1.844 & 2.996 & 1.242 & 96 \\
\hline FACULDADES ISOLADAS & 20 & 1.810 & 4.332 & 1.774 & - \\
\hline $\begin{array}{lll}\text { FACULDADES, } & \text { ESCOLAS } & \text { E } \\
\text { INSTITUTOS. } & & \\
\end{array}$ & - & - & - & - & 400 \\
\hline $\begin{array}{lcl}\text { CENTRO DE } & \text { EDUCAÇÃO } \\
\text { TECNOLOGICA } & \\
\end{array}$ & - & - & - & - & - \\
\hline TOTAL & 81 & 9.931 & 23.206 & 8.702 & 1.432 \\
\hline \multicolumn{6}{|c|}{1999} \\
\hline UNIVERSIDADES & 60 & 8.492 & 24.828 & 7.316 & 1.347 \\
\hline CENTROS UNIVERSITÁRIOS/ & - & 2.958 & 7.504 & 2.394 & 322 \\
\hline FACULDADES INTEGRADAS & 12 & 930 & 2.335 & 756 & 151 \\
\hline FACULDADES ISOLADAS & 39 & - & - & - & - \\
\hline $\begin{array}{lll}\text { FACULDADES, } & \text { ESCOLAS } & \text { E } \\
\text { INSTITUTOS. } & & \\
\end{array}$ & - & 3.500 & 7.067 & 2.871 & 409 \\
\hline $\begin{array}{lrl}\text { CENTRO DE } & \text { EDUCAÇÃO } \\
\text { TECNOLOGICA } & \\
\end{array}$ & - & - & - & - & - \\
\hline TOTAL & 102 & 15.880 & 41.734 & 13.337 & 2.229 \\
\hline \multicolumn{6}{|c|}{2000} \\
\hline UNIVERSIDADES & 83 & 11.691 & 38.436 & 8.026 & $(-)$ \\
\hline CENTROS UNIVERSITÁRIOS/ & 32 & 5.158 & 8.755 & 3.561 & $(-)$ \\
\hline FACULDADES INTEGRADAS & 18 & 2.158 & 3.047 & 1.351 & $(-)$ \\
\hline FACULDADES ISOLADAS & - & - & - & - & $(-)$ \\
\hline $\begin{array}{lll}\text { FACULDADES, } & \text { ESCOLAS } & \text { E } \\
\text { INSTITUTOS. } & & \\
\end{array}$ & 76 & 9.093 & 13.442 & 6.073 & $(-)$ \\
\hline $\begin{array}{lcc}\text { CENTRO DE } & \text { EDUCAÇÃO } \\
\text { TECNOLOGICA } & \\
\end{array}$ & - & - & - & - & $(-)$ \\
\hline TOTAL & 283 & 28.098 & 63.680 & 19.011 & $(-)$ \\
\hline \multicolumn{6}{|c|}{2001} \\
\hline UNIVERSIDADES & 99 & 13.405 & 29.989 & 8.691 & 2.923 \\
\hline CENTROS UNIVERSITÁRIOS/ & 40 & 7.047 & 12.881 & 4.991 & 662 \\
\hline FACULDADES INTEGRADAS & 23 & 2.533 & 2.967 & 1.346 & 307 \\
\hline FACULDADES ISOLADAS & - & - & - & - & - \\
\hline $\begin{array}{lll}\text { FACULDADES, } & \text { ESCOLAS } & \text { E } \\
\text { INSTITUTOS. } & & \\
\end{array}$ & 139 & 15.278 & 21.276 & 10.151 & 502 \\
\hline $\begin{array}{lrl}\text { CENTRO DE } & \text { EDUCAÇÃO } \\
\text { TECNOLOGICA } & \\
\end{array}$ & 1 & 120 & 1.240 & 120 & 75 \\
\hline TOTAL & 302 & 38.383 & 68.353 & 25.299 & 4.394 \\
\hline
\end{tabular}


CONTINUAÇÃO...

\begin{tabular}{|c|c|c|c|c|c|}
\hline \multicolumn{6}{|c|}{2002} \\
\hline UNIVERSIDADES & 107 & 13.716 & 38.003 & 1.913 & 3.828 \\
\hline CENTROS UNIVERSITÁRIOS/ & 42 & 7.417 & 9.669 & 3.702 & 1.329 \\
\hline FACULDADES INTEGRADAS & 27 & 3.135 & 2.308 & 1.307 & 666 \\
\hline FACULDADES ISOLADAS & - & - & - & - & - \\
\hline $\begin{array}{l}\text { FACULDADES, ESCOLAS } \\
\text { INSTITUTOS. }\end{array}$ & 196 & 24.694 & 27.546 & 12.496 & 892 \\
\hline $\begin{array}{lrl}\text { CENTRO DE } & \text { EDUCAÇÃO } \\
\text { TECNOLOGICA } & \\
\end{array}$ & 1 & 610 & 1.152 & 219 & - \\
\hline TOTAL & 377 & 49.572 & 78.678 & 25.636 & 6.715 \\
\hline \multicolumn{6}{|c|}{2003} \\
\hline UNIVERSIDADES & 119 & 14.317 & 35.939 & 7.090 & 4.363 \\
\hline CENTROS UNIVERSITÁRIOS/ & 44 & 7.149 & 7.277 & 3.283 & 1.648 \\
\hline FACULDADES INTEGRADAS & 34 & 3.922 & 2.612 & 1.409 & 934 \\
\hline FACULDADES ISOLADAS & - & - & - & - & - \\
\hline $\begin{array}{lll}\text { FACULDADES, } & \text { ESCOLAS } & \text { E } \\
\text { INSTITUTOS. } & & \\
\end{array}$ & 227 & 29.557 & 31.498 & 12.371 & 2.155 \\
\hline $\begin{array}{lcc}\text { CENTRO DE } & \text { EDUCAÇÃO } \\
\text { TECNOLOGICA } & \\
\end{array}$ & 6 & 790 & 2.482 & 288 & 83 \\
\hline TOTAL & 430 & 55.735 & 79.808 & 24.441 & 9.183 \\
\hline \multicolumn{6}{|c|}{2004} \\
\hline UNIVERSIDADES & 125 & 14.313 & 37.842 & 6.269 & $(-)$ \\
\hline CENTROS UNIVERSITÁRIOS/ & 61 & 8.879 & 9.424 & 3.383 & $(-)$ \\
\hline FACULDADES INTEGRADAS & 32 & 3.959 & 2.457 & 1.115 & $(-)$ \\
\hline FACULDADES ISOLADAS & - & - & - & - & $(-)$ \\
\hline $\begin{array}{lll}\text { FACULDADES, } & \text { ESCOLAS } & \text { E } \\
\text { INSTITUTOS. } & & \\
\end{array}$ & 236 & 30.920 & 29.242 & 9.745 & $(-)$ \\
\hline $\begin{array}{lcr}\text { CENTRO DE } & \text { EDUCAÇÃO } \\
\text { TECNOLOGICA E FACULDADE } \\
\text { DE TECNOLOGIA }- \text { CET/FAT }\end{array}$ & 7 & 1.066 & 3.024 & 452 & $(-)$ \\
\hline TOTAL & 461 & 59.137 & 81.995 & 20.864 & $(-)$ \\
\hline \multicolumn{6}{|c|}{2005} \\
\hline UNIVERSIDADES & 131 & 14.524 & 29.896 & 6.145 & 5.214 \\
\hline CENTROS UNIVERSITÁRIOS/ & 69 & 6.935 & 6.712 & 2.508 & 2.408 \\
\hline FACULDADES INTEGRADAS & 29 & 2.711 & 1.530 & 731 & 644 \\
\hline FACULDADES ISOLADAS & - & - & - & - & - \\
\hline $\begin{array}{lll}\text { FACULDADES, } & \text { ESCOLAS } & \text { E } \\
\text { INSTITUTOS. } & & \end{array}$ & 237 & 25.406 & 20.366 & 7.267 & 4.651 \\
\hline CET/FAT & 10 & 776 & 1.179 & 401 & 238 \\
\hline TOTAL & 476 & 50.352 & 59.683 & 17.050 & 13.155 \\
\hline \multicolumn{6}{|c|}{2006} \\
\hline UNIVERSIDADES & 134 & 13.910 & 2.877 & 15.074 & 4.016 \\
\hline CENTROS UNIVERSITÁRIOS/ & 65 & 7.275 & 6.254 & 2.179 & 1.943 \\
\hline FACULDADES INTEGRADAS & 28 & 2.871 & 1.664 & 728 & 620 \\
\hline FACULDADES ISOLADAS & - & - & - & - & - \\
\hline $\begin{array}{llc}\text { FACULDADES, } & \text { ESCOLAS } & \text { E } \\
\text { INSTITUTOS. } & & \\
\end{array}$ & 249 & 28.446 & 20.564 & 6.107 & 4.519 \\
\hline CET/FAT & 10 & 820 & 866 & 414 & 121 \\
\hline TOTAL & 486 & 53.322 & 58.125 & 15.074 & 11.219 \\
\hline \multicolumn{6}{|c|}{2007} \\
\hline UNIVERSIDADES & 155 & 14.449 & 25.517 & 5.916 & $(-)$ \\
\hline CENTROS UNIVERSITÁRIOS/ & 71 & 7.135 & 3.949 & 1.457 & $(-)$ \\
\hline FACULDADES INTEGRADAS & 31 & 3.056 & 1.760 & 623 & $(-)$ \\
\hline FACULDADES ISOLADAS & - & - & - & - & $(-)$ \\
\hline $\begin{array}{lll}\text { FACULDADES, } & \text { ESCOLAS } & \text { E } \\
\text { INSTITUTOS. } & & \\
\end{array}$ & 250 & 25.242 & 14.905 & 4.771 & $(-)$ \\
\hline CET/FAT & 19 & 1.240 & 4.166 & 790 & $(-)$ \\
\hline TOTAL & 526 & 51.123 & 50.297 & 13.557 & $(-)$ \\
\hline
\end{tabular}


CONTINUAÇÃO...

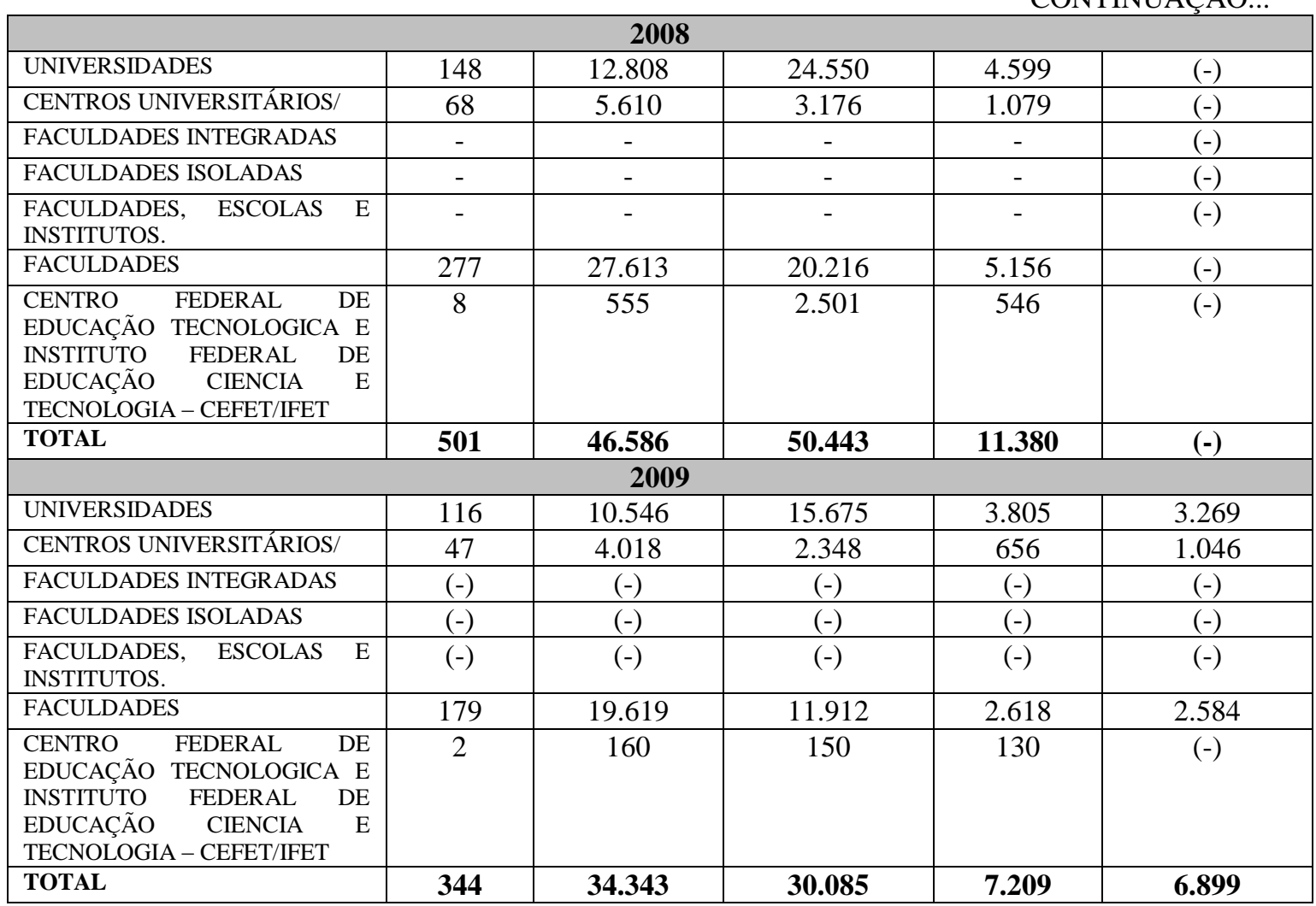

QUADRO 6 - NÚMERO DE CURSOS, VAGAS OFERECIDAS, CANDIDATOS INSCRITOS E INGRESSOS POR VESTIBULAR E OUTROS PROCESSOS SELETIVOS E CONCLUINTES NO CURSO DE GRADUAÇÃO EM TURISMO POR ORGANIZAÇÃO ACADÊMICA NO PERÍODO DE 1995 A 2009. QUADRO ELABORADO POR: MARLENE MATIAS.

FONTE: SINOPSE ESTATÍSTICA E MICRODADOS DO CENSO DA EDUCAÇÃO SUPERIOR/ MEC/INEP/DEED DE 1995 A 2009.

NOTAS:

Em 1996 os concluintes dos Centros Universitários foram computados junto com os das Faculdades Integradas; Em 1998 os concluintes dos Centros Universitários foram desmembrados das Faculdades Integradas;

Em 1998 os cursos dos Centros Universitários aparecem computados junto com os das Isoladas;

Em 1999 as Faculdades Isoladas passaram a integrar as Faculdades, Escolas e Institutos;

Em 2000 os cursos dos Centros Universitários foram desmembrados das Faculdades Isoladas;

(-) dado não disponível;

Em 2004 os Centros de Educação Tecnológica foram agregados às Faculdades de Tecnologia, ficando CET/FAT;

Em 2008 as terminologias Faculdades, Escolas e Institutos e Faculdades Integradas foram suprimidas passando a denominarem-se Faculdades;

Em 2008 a terminologia CET/FAT foi substituída por Centro Federal de Educação Tecnológica e Instituto Federal de Educação, Ciência e Tecnologia - CEFET/IFET.

Os dados mostrados anteriormente sobre o ensino de graduação em Turismo desde a sua implantação no Brasil até o ano de 2009, mostram sua evolução e tendências.

No ano de 2010 o Ministério do Turismo - MTUR, por meio do Instituto Brasileiro de Turismo - EMBRATUR, realizou uma pesquisa para identificar somente a 
oferta de cursos de graduação em Turismo no país. Essa pesquisa identificou um total de 559 instituições de ensino que possuíam ou já possuíram cursos de Turismo.

Dessas 559 instituições identificadas a pesquisa chegou ao seguinte resultado:

- 326 instituições responderam possuir curso de Turismo;

- 137 instituições foram fechadas ou não ofereciam mais o curso;

- 96 não responderam à pesquisa ou ofereciam o curso, mas não formaram turma.

Se levar em conta somente as instituições que responderam possuir curso em funcionamento, pode-se constatar a diminuição da oferta de cursos de Turismo, tendência essa já sinalizada pela Sinopse Estatística e Microdados do Censo da Educação Superior, a partir do ano de 2008.

Isso leva a entender que o ensino de graduação de Turismo no país, está passando por um ajustamento de mercado, isto é, está buscando equilibrar a oferta de cursos e vagas às demandas do mercado.

\section{2 - CURSOS PRESENCIAIS DE GRADUAÇÃO DAS ÁREAS AFINS DO TURISMO}

O ensino de graduação de Áreas Afins ao Turismo iniciou-se em 1978 com a criação do primeiro curso de Hotelaria, seu crescimento apresentou-se bastante moderado, isto é, somente na década de 1980, é que irão surgir outros dois cursos de Hotelaria, sendo um de graduação em 1984 e um de Tecnologia em 1989. Encerrando os anos de 1980, mais especificamente em 1990, é criado o primeiro curso de Turismo e Hotelaria, que se apresenta como uma proposta inovadora que integra as duas áreas do conhecimento que até então eram ensinadas de forma separada. A seguir o Quadro 7 mostra a evolução do ensino das Áreas Afins ao Turismo no período de 1978 a 1990.

\begin{tabular}{|c|c|c|}
\hline Ano & Curso de Hotelaria & $\begin{array}{c}\text { Curso de Turismo e } \\
\text { Hotelaria }\end{array}$ \\
\hline 1978 & 1 & 0 \\
\hline 1979 & 0 & 0 \\
\hline 1980 & 0 & 0 \\
\hline 1981 & 0 & 0 \\
\hline 1982 & 0 & 0 \\
\hline 1983 & 0 & 0 \\
\hline
\end{tabular}


CONTINUAÇÃO...

\begin{tabular}{|l|l|l|}
\hline 1984 & 1 & 0 \\
\hline 1985 & 0 & 0 \\
\hline 1986 & 0 & 0 \\
\hline 1987 & 0 & 0 \\
\hline 1988 & 0 & 0 \\
\hline 1989 & $1^{1}$ & 0 \\
\hline 1990 & 0 & 1 \\
\hline TOTAL & $\mathbf{3}$ & $\mathbf{1}$ \\
\hline
\end{tabular}

QUADRO 7 - EVOLUÇÃO DOS CURSOS DE HOTELARIA E TURISMO E HOTELARIA, NO PERÍODO DE 1978 A 1990.

QUADRO ELABORADO POR: MARLENE MATIAS

FONTE: TRIGO (1991; 2000) E REJOWSKI (1996)

NOTA: (1) Curso superior de Tecnologia.

Como já mencionado no item 2.1 Origens, Evolução e Tendências dos Cursos de Graduação em Turismo, não se têm dados referentes ao período 1991 a 1994, que permitam analisar o crescimento da atividade. Mas, segundo Ansarah e Rejowski (1996, p. 38), nesse período existiam no país 49 cursos, sendo 40 de Turismo, 8 de hotelaria e 1 de Turismo e Hotelaria.

A partir de 1995 a Sinopse Estatística e Microdados do Censo da Educação Superior passou a apresentar dados sobre o assunto que possibilitam identificar a evolução e as tendências do ensino de graduação das Áreas Afins ao Turismo.

O Quadro 8 a seguir mostra a dinâmica do ensino de graduação das Áreas Afins ao Turismo, onde se pode perceber que de 1971 quando surgiu o primeiro curso de Turismo até 1997, existia apenas o ensino da área de Hotelaria, exceto um curso de Turismo e Hotelaria que foi criado em 1990.

Ainda no Quadro 8 abaixo, em 1998 aparecem os cursos de Turismo e de Hotelaria e de Lazer, Recreação e Eventos, sendo que este último teve curta duração, deixando de existir no ano 2000.

Em 1999 é criado o curso de Tecnologia de Gestão de Lazer, que segundo a Sinopse Estatística e Microdados do Censo de Educação Superior teve apenas um único vestibular.

O ano 2000 apresenta a criação de cursos de Áreas Afins ao Turismo de forma mais acentuada, isto é, disciplinas que faziam parte da matriz curricular do Curso de Turismo começam a ser transformadas em cursos. Isso marca o aumento da oferta de cursos e também de vagas de outras áreas do conhecimento, podendo causar a 
diminuição do interesse pela área do ensino do Turismo, por esta apresentar uma formação generalista.

\begin{tabular}{|c|c|c|c|c|c|c|c|c|c|c|c|c|c|c|c|}
\hline \multirow[t]{2}{*}{ CURSOS } & \multicolumn{15}{|c|}{ ANOS } \\
\hline & 1995 & 1996 & 1997 & 1998 & 1999 & 2000 & 2001 & 2002 & 2003 & 2004 & 2005 & 2006 & 2007 & 2008 & 2009 \\
\hline HOTELARIA & 5 & 7 & 8 & 12 & 36 & 13 & 29 & 34 & 43 & 52 & 64 & 67 & 86 & 83 & 30 \\
\hline $\begin{array}{ll}\text { TURISMO } & \text { E } \\
\text { HOTELARIA } & \end{array}$ & - & - & - & 7 & 9 & 19 & 18 & 18 & 30 & 51 & 54 & 55 & 20 & 22 & 17 \\
\hline $\begin{array}{ll}\text { LAZER, } \\
\text { RECREAÇÃO } \\
\text { EVENTOS. }\end{array}$ & - & - & - & 1 & 1 & - & - & - & - & - & - & - & - & - & - \\
\hline $\begin{array}{ll}\text { TECNOLOGIA } & \text { DE } \\
\text { GESTÃO } & \text { DE } \\
\text { LAZER } & \end{array}$ & - & - & - & - & 1 & - & - & - & - & - & - & - & - & - & - \\
\hline $\begin{array}{l}\text { GASTRONOMIA1 } \\
\text { (Bacharelado) }\end{array}$ & - & - & - & - & - & 1 & 2 & 5 & 9 & 14 & 15 & 34 & 47 & 71 & 6 \\
\hline $\begin{array}{l}\text { GASTRONOMIA } \\
\text { (Tecnólogo) }\end{array}$ & - & - & - & - & - & - & - & - & - & - & - & - & - & - & 74 \\
\hline $\begin{array}{l}\text { HOTELARIA } \\
\text { RESTAURANTE }\end{array}$ & - & - & - & - & - & 1 & 1 & 2 & 3 & 1 & - & - & - & - & 1 \\
\hline $\begin{array}{l}\text { CIENCIA } \\
\text { AERONAUTICA }\end{array}$ & - & - & - & - & - & 10 & 10 & 11 & 10 & 14 & 15 & 14 & 13 & 12 & 8 \\
\hline $\begin{array}{l}\text { TECNOLOGIA DE } \\
\text { NAVEGAÇÃO }\end{array}$ & - & - & - & - & - & 2 & 2 & 2 & 2 & 3 & 3 & 3 & - & - & - \\
\hline $\begin{array}{ll}\text { LAZER } & \text { E } \\
\text { TURISMO } & \end{array}$ & - & - & - & - & - & 1 & 2 & 2 & 2 & 4 & 7 & 7 & 5 & 4 & 7 \\
\hline $\begin{array}{ll}\text { RECREAÇÃO } & \text { E } \\
\text { LAZER }\end{array}$ & - & - & - & - & - & 1 & 1 & 3 & 5 & 7 & 8 & 5 & - & - & 14 \\
\hline TRANSPORTES & - & - & - & - & - & - & 1 & 4 & 5 & 3 & 6 & 9 & 9 & 16 & 9 \\
\hline AVIAÇÃO & - & - & - & - & - & - & 2 & 1 & 1 & 4 & 5 & 6 & 6 & 8 & - \\
\hline $\begin{array}{ll}\text { TURISMO } & \text { E } \\
\text { VIAGENS } & \end{array}$ & - & - & - & - & - & - & - & 1 & - & - & - & - & - & - & \\
\hline EVENTOS & - & - & - & - & - & - & - & 2 & 3 & 7 & 17 & 10 & 35 & 43 & 32 \\
\hline $\begin{array}{l}\text { PLANEJAMENTO } \\
\text { E ORGANIZAÇÃO } \\
\text { DO TURISMO } \\
\end{array}$ & - & - & - & - & - & - & - & - & 1 & - & 3 & 3 & - & - & 4 \\
\hline $\begin{array}{ll}\text { OPERAÇÃO } & \text { DE } \\
\text { AERONAVES } & \end{array}$ & - & - & - & - & - & - & - & - & - & - & - & 1 & - & - & 1 \\
\hline $\begin{array}{l}\text { NAVEGAÇÃO } \\
\text { FLUVIAL }\end{array}$ & - & - & - & - & - & - & - & - & - & - & - & - & 2 & - & 1 \\
\hline $\begin{array}{l}\text { SERVIÇO } \\
\text { AEROPORTUARIO }\end{array}$ & - & - & - & - & - & - & - & - & - & - & - & - & 5 & 2 & 2 \\
\hline $\begin{array}{l}\text { SERVIÇO } \\
\text { PORTUARIO }\end{array}$ & - & - & - & - & - & - & - & - & - & - & - & - & 3 & 6 & 7 \\
\hline $\begin{array}{l}\text { HOTELARIA } \\
\text { (TECNOLOGO) }\end{array}$ & - & - & - & - & - & - & - & - & - & - & - & - & - & 2 & 43 \\
\hline $\begin{array}{l}\text { GESTÃO DE } \\
\text { TURISMO } \\
\text { (TECNOLOGO) }\end{array}$ & - & - & - & - & - & - & - & - & - & - & - & - & - & 5 & 57 \\
\hline TOTAL & 5 & 7 & 8 & 20 & 47 & 48 & 68 & 85 & 114 & 160 & 197 & 214 & 231 & 374 & 313 \\
\hline
\end{tabular}

QUADRO 8 - NÚMERO DE CURSOS DE GRADUAÇÃO EM TURISMO E ÁREAS AFINS NO BRASIL NO PERÍODO DE 1995 A 2009.

QUADRO ELABORADO POR: MARLENE MATIAS.

FONTE: SINOPSE ESTATISTICA E MICRODADOS DO CENSO DA EDUCAÇÃO SUPERIOR/ MEC/INEP/DEED DE 1995 A 2009.

NOTAS: (1) a partir de 2009 o curso de Tecnólogo em Gastronomia foi desmembrado do Curso de Bacharelado em Gastronomia.

As disciplinas de cursos de Turismo que foram transformadas em cursos e as Áreas Afins ao Turismo que tinham seus cursos funcionando em 2009, conforme mostra o Quadro 8 acima, são: 
- Gastronomia (Tecnólogo);

- Gastronomia (Bacharelado);

- Ciência Aeronáutica;

- Lazer e Turismo;

- Transportes;

- Eventos;

- Serviço Aeroportuário;

- Serviço Portuário;

- Hotelaria (Tecnólogo);

- Gestão do Turismo (Tecnólogo);

- Hotelaria e Restaurantes;

- Recreação e Lazer;

- Planejamento e Organização do Turismo;

- Operação de Aeronaves;

- Navegação Fluvial.

Outras áreas que tiveram seus cursos criados após o ano 2000 e encerrados antes de 2009, conforme mostra o Quadro 8 acima são:

- Tecnologia de Navegação;

- Recreação e Lazer;

- Turismo e Viagens;

- Navegação Fluvial;

- Lazer, Recreação e Eventos;

- Tecnologia de Gestão de Lazer.

No período entre 1978 a 2009, 22 Áreas Afins ao Turismo tiveram seus cursos criados. No início o crescimento foi moderado tanto em número de cursos, quanto em número de vagas e áreas do conhecimento. Mas, a partir de 1999 começaram a surgir cursos de novas áreas, e conforme esses cursos foram aceitos pelo mercado, seus números foram aumentando, e se rejeitados deixavam de existir.

Dentre os cursos das áreas Afins que mais tiveram aceitação no mercado em 2009 estão:

- Gastronomia (Tecnólogo) (74 cursos);

- Gestão de Turismo (Tecnólogo) (57 cursos); 
- Hotelaria (Tecnólogo) (43 cursos);

- Eventos (32 cursos);

- Hotelaria (Bacharelado) (30 cursos)

- Turismo e Hotelaria (17 cursos)

- Transportes (16 cursos);

- Ciência Aeronáutica (12 cursos).

Devido a grande quantidade de Áreas Afins (22) e de cursos (313) em 2009, torna-se difícil realizar uma análise de cada curso, para verificar seu comportamento ao longo dos anos, esclarecendo-se não ser esse o foco da presente pesquisa.

A seguir no Quadro 9 se apresenta o comportamento de todo o conjunto das Áreas Afins ao Turismo, no período de 1995 a 2009, em termos de número de vagas, candidatos inscritos, ingressos e número de vagas não preenchidas.

Com relação ao número de vagas ofertadas verificou-se que seu crescimento foi bastante variado ao longo do período, em 1998 cresceu 211,8\% em relação ao ano anterior, depois continuou crescendo em percentuais menores, em 1999 (50,9\%), subindo novamente em 2000 para 141,8\%. Nos outros anos apresentou oscilações moderadas.

Sobre o número de candidatos inscritos no vestibular o comportamento também é de crescimento ao longo do período, apresentou índices negativos somente em 2002 (4,8\%) e em 2007 (-4\%), sendo que em 2009 ocorreu crescimento de 67,0\% em relação ao ano anterior.

Com relação ao número de ingressos o período apresentou crescimento com oscilações moderadas, exceto no ano 2000 (92\%), em 2009 o índice de ingressos apresentou taxas negativas de $-3,4 \%$ em relação a 2008 .

Mas, ao comparar o número de vagas em relação ao número de ingressos percebe-se que os percentuais de vagas não preenchidas ao longo do período na sua maioria estão acima de 50\%, sendo que a maior taxa verificada foi em $2009(63,1 \%)$.

\begin{tabular}{|c|c|c|c|c|c|c|c|}
\hline ANO & $\begin{array}{c}\text { NÚMERO DE } \\
\text { VAGAS } \\
\text { OFERECIDAS }\end{array}$ & $\begin{array}{c}\text { \% DE } \\
\text { VARIAÇÃO } \\
\text { DE } \\
\text { VAGAS/ANO }\end{array}$ & $\begin{array}{c}\text { CANDIDATOS } \\
\text { INSCRITOS }\end{array}$ & $\begin{array}{c}\text { \% DE } \\
\text { VARIAÇÃO } \\
\text { CANDIDATO } \\
\text { INSCRITO/ANO }\end{array}$ & INGRESSOS & $\begin{array}{c}\text { \% DE } \\
\text { VARIAÇÃO } \\
\text { INGRESSO/ANO }\end{array}$ & $\begin{array}{c}\text { \% DE VAGAS } \\
\text { NÃO } \\
\text { PREENCHIDAS }\end{array}$ \\
\hline 1995 & 608 & $(-)$ & $(-)$ & $(-)$ & $(-)$ & $(-)$ & $(-)$ \\
\hline 1996 & 630 & 3,6 & $(-)$ & $(-)$ & $(-)$ & $(-)$ & $(-)$ \\
\hline 1997 & 660 & 4,7 & $(-)$ & $(-)$ & $(-)$ & $(-)$ & $(-)$ \\
\hline 1998 & 2.058 & 211,8 & $(-)$ & $(-)$ & $(-)$ & $(-)$ & $(-)$ \\
\hline
\end{tabular}


CONTINUAÇÃO...

\begin{tabular}{|c|c|c|c|c|c|c|c|}
\hline 1999 & 3.107 & 50,9 & 8.563 & $(-)$ & 2.716 & $(-)$ & 12,5 \\
\hline 2000 & 7.515 & 141,8 & 14.618 & 70,7 & 5.225 & 92,3 & 30,4 \\
\hline 2001 & 8.242 & 9,6 & 17.570 & 20,1 & 5.921 & 13,3 & 28,1 \\
\hline 2002 & 10.786 & 30,0 & 16.726 & $-4,8$ & 6.425 & 8,5 & 40,4 \\
\hline 2003 & 14.753 & 36,7 & 18.662 & 11,5 & 7.160 & 11,4 & 51,4 \\
\hline 2004 & 18.724 & 26,9 & 21.435 & 14,8 & 8.040 & 12,2 & 57,0 \\
\hline 2005 & 20.722 & 10,6 & 25.077 & 16,9 & 9.243 & 14,9 & 55,3 \\
\hline 2006 & 23.156 & 11,7 & 31.345 & 24,9 & 10.434 & 12,2 & 54,9 \\
\hline 2007 & 24.396 & 5,3 & 26.930 & $-4,0$ & 10.523 & 0,85 & 56,8 \\
\hline 2008 & 32.761 & 34,2 & 37.057 & 37,6 & 13.543 & 28,6 & 58,6 \\
\hline 2009 & 35.469 & 8,2 & 61.906 & 67,0 & 13.076 & $-3,4$ & 63,1 \\
\hline
\end{tabular}

QUADRO 9 - NÚMERO DE VAGAS, PERCENTUAL DE VARIAÇÃO ANUAL DE VAGAS, INGRESSOS POR VESTIBULAR E OUTROS PROCESSOS SELETIVOS, PERCENTUAL DE VARIAÇÃO DE INGRESSO E PERCENTUAL DE VAGAS NÃO PREENCHIDAS EM RELAÇÃO AO NÚMERO DE VAGAS OFERECIDAS NOS CURSOS DE GRADUAÇÃO DAS ÁREAS AFINS AO TURISMO NO PERÍODO DE 1995 A 2009.

QUADRO ELABORADO POR: MARLENE MATIAS.

FONTE: SINOPSE ESTATÍSTICA E MICRODADOS DO CENSO DA EDUCAÇÃO SUPERIOR/MEC/INEP/SEEC DE 1995 A 2009.

Devido à escassez de dados sobre o desenvolvimento de cada curso das Áreas Afins ao Turismo mostra-se a seguir no Quadro 10 o desempenho dos cursos que estavam funcionando em 2009, em termos de vagas ofertadas, candidatos inscritos, ingressos e concluintes.

\begin{tabular}{|c|c|c|c|c|}
\hline CURSO & $\begin{array}{l}\text { NÚMERO DE } \\
\text { VAGAS } \\
\text { OFERECIDAS }\end{array}$ & $\begin{array}{l}\text { CANDIDATOS } \\
\text { INSCRITOS }\end{array}$ & INGRESSOS & CONCLUINTES \\
\hline $\begin{array}{l}\text { GASTRONOMIA } \\
\text { (BACHARELADO) }\end{array}$ & 550 & 1840 & 390 & 115 \\
\hline $\begin{array}{l}\text { GASTRONOMIA } \\
\text { (TECNÓLOGO) }\end{array}$ & 10.316 & 18.246 & 5.358 & 2.464 \\
\hline $\begin{array}{l}\text { HOTELARIA } \\
(\text { BACHARELADO) }\end{array}$ & 2.747 & 3.079 & 693 & 607 \\
\hline $\begin{array}{l}\text { HOTELARIA } \\
\text { (TECNÓLOGO) }\end{array}$ & 5.380 & 5.306 & 1.103 & 831 \\
\hline $\begin{array}{l}\text { HOTELARIA E } \\
\text { RESTAURANTE }\end{array}$ & 60 & 39 & 19 & 11 \\
\hline AVIAÇÃO & 1.360 & 1.987 & 619 & 93 \\
\hline $\begin{array}{l}\text { CIÊNCIA } \\
\text { AERONAUTICA }\end{array}$ & 930 & 1.104 & 371 & 162 \\
\hline NAVEGAÇÃO FLUVIAL & 40 & 73 & 42 & 15 \\
\hline $\begin{array}{l}\text { OPERAÇÃO DE } \\
\text { AERONAVES }\end{array}$ & 29 & 51 & 19 & - \\
\hline $\begin{array}{l}\text { SERVIÇO } \\
\text { AEROPORTUARIO }\end{array}$ & 100 & - & - & 25 \\
\hline SERVIÇO PORTUARIO & 995 & 1.914 & 539 & 168 \\
\hline TRANSPORTES & 1.560 & 2.469 & 812 & 208 \\
\hline EVENTOS & 4.025 & 5.404 & 1.185 & 516 \\
\hline
\end{tabular}


CONTINUAÇÃO...

\begin{tabular}{|l|c|c|c|c|}
\hline $\begin{array}{l}\text { GESTÃO DE TURISMO } \\
\text { (TECNOLOGO) }\end{array}$ & 4.688 & 17.900 & 1.540 & 869 \\
\hline LAZER E TURISMO & 304 & 1.589 & 214 & 106 \\
\hline $\begin{array}{l}\text { PLANEJAMENTO E } \\
\text { ORGANIZAÇÃO DO } \\
\text { TURISMO }\end{array}$ & 145 & 15 & 10 & 80 \\
\hline TURISMO E HOTELARIA & 2.240 & 890 & 162 & 347 \\
\hline TOTAL & $\mathbf{3 5 . 4 6 9}$ & $\mathbf{6 1 . 9 0 6}$ & $\mathbf{1 3 . 0 7 6}$ & - \\
\hline
\end{tabular}

QUADRO 10 - NÚMERO DE VAGAS, CANDIDATOS INSCRITOS, INGRESSOS POR VESTIBULAR E OUTROS PROCESSOS SELETIVOS, E CONCLUINTES DOS CURSOS DE GRADUAÇÃO DAS ÁREAS AFINS AO TURISMO EM 2009. QUADRO ELABORADO POR: MARLENE MATIAS. FONTE: SINOPSE ESTATÍSTICA E MICRODADOS DO CENSO DA EDUCAÇÃO SUPERIOR/MEC/INEP/SEEC DE 1995 A 2009

Ao se comparar os dados do Quadro 6 que apresenta os dados dos cursos de Turismo referentes a 2009, com os do Quadro 10 acima que mostra o desempenho dos cursos das Áreas Afins ao Turismo, no mesmo período, verifica-se que os cursos das 17 Áreas Afins ao Turismo ofereceram 3,2\% de vagas a mais, tiveram 105,7\% de candidatos inscritos a mais, e obtiveram $81,3 \%$ de mais ingressantes. Isso demonstra que os cursos das áreas Afins ao Turismo estão fazendo concorrência direta com os cursos de Turismo, porque os candidatos preferem buscar uma formação mais específica, isto é, de uma determinada área de interesse do que uma formação generalista que lhe dê uma visão abrangente do que seja a área de Turismo.

\section{3 - CURSOS DE EDUCAÇÃO A DISTÂNCIA DE TURISMO E DAS ÁREAS AFINS AO TURISMO}

A Educação a Distância existe desde 1904, no Brasil, era realizada por meio do correio postal e posteriormente pelo Instituto Universal Brasileiro, entre 1996 e 1997 nasce a Universidade Virtual do Brasil - UVB. Em dezembro de 1996 foi oficializada a Educação a Distância para todos os níveis de ensino no país (PEÑA, 2010). Ela foi instituída no país para propiciar o acesso a educação e formação de um maior número de pessoas que por diversos fatores estavam impossibilitadas de frequentar cursos presenciais.

Com relação à existência de cursos de Turismo e das Áreas Afins ao Turismo as informações ainda são bastante escassas, mas as poucas existentes possibilitam verificar 
que esse tipo de educação está sendo bem recebido, conforme apresentou o Censo da Educação Superior de 2009.

O Quadro 11 abaixo mostra o número de cursos de Turismo e das Áreas afins que estavam funcionando em 2009.

\begin{tabular}{|l|c|}
\hline \multicolumn{1}{|c|}{ CURSOS } & NÚMERO DE CURSOS \\
\hline TURISMO & 4 \\
\hline GESTÃO DO TURISMO & 3 \\
\hline HOTELARIA (BACHARELADO) & 1 \\
\hline HOTELARIA (TECNOLOGO) & 1 \\
\hline SERVIÇO AEROPORTUARIO & 1 \\
\hline TOTAL & $\mathbf{1 0}$ \\
\hline
\end{tabular}

QUADRO 11 - NÚMERO DE CURSOS DE GRADUAÇÃO DE EDUCAÇÃO A DISTANCIA EM TURISMO E DAS ÁREAS AFINS AO TURISMO EM 2009.

QUADRO ELABORADO POR: MARLENE MATIAS.

FONTE: SINOPSE ESTATÍSTICA E MICRODADOS DO CENSO DA EDUCAÇÃO SUPERIOR/MEC/INEP/DEED/IF-CEFET DE 1995 A 2009.

A seguir o Quadro 12 apresenta o comportamento dos cursos de Educação à Distância tanto de Turismo como das Áreas Afins ao Turismo em 2009, em termos de número de vagas ofertadas, candidatos inscritos e ingressos.

\begin{tabular}{|l|c|c|c|}
\hline \multicolumn{1}{|c|}{ CURSO } & $\begin{array}{c}\text { NÚMERO DE VAGAS } \\
\text { OFERECIDAS }\end{array}$ & $\begin{array}{c}\text { CANDIDATOS } \\
\text { INSCRITOS }\end{array}$ & INGRESSOS \\
\hline $\begin{array}{l}\text { HOTELARIA } \\
\text { (BACHARELADO) }\end{array}$ & 210 & 411 & 163 \\
\hline $\begin{array}{l}\text { HOTELARIA } \\
\text { (TECNÓLOGO) }\end{array}$ & 50 & 248 & 97 \\
\hline $\begin{array}{l}\text { GESTÃO DE TURISMO } \\
\text { (TECNOLOGO) }\end{array}$ & 2.000 & 187 & 92 \\
\hline SERVIÇO AERONAUTICO & 90 & 45 & - \\
\hline TURISMO & 3.270 & 2.012 & 855 \\
\hline TOTAL & $\mathbf{5 . 6 2 0}$ & $\mathbf{2 . 9 0 3}$ & $\mathbf{1 . 2 0 7}$ \\
\hline
\end{tabular}

QUADRO 12 - NÚMERO DE VAGAS OFERTADAS, CANDIDATOS INSCRITOS E INGRESSOS DOS CURSOS DE GRADUAÇÃO DE EDUCAÇÃO A DISTÂNCIA EM TURISMO E DAS ÁREAS AFINS AO TURISMO EM 2009.

QUADRO ELABORADO POR: MARLENE MATIAS.

FONTE: SINOPSE ESTATÍSTICA E MICRODADOS DO CENSO DA EDUCAÇÃO SUPERIOR/MEC/INEP/DEED/IF-CEFET DE 1995 A 2009.

Atualmente tanto os cursos de Turismo quanto os cursos das Áreas Afins ao Turismo terão como concorrentes os cursos de graduação de Educação à Distância, porque eles poderão atingir um número maior de candidatos, devido a não exigência presencial para a realização dos estudos. 


\section{CONSIDERAÇÕES FINAIS}

Ao analisar o ensino do Turismo no Brasil pode-se constatar que houve um crescimento no número de cursos de Turismo tanto na área pública, quanto na área privada.

O maior crescimento foi identificado a partir dos anos de 1990, depois continuou pelos anos 2000, atingindo 526 cursos, em 2007 (vide Quadro 3). O mesmo pode ser observado em relação ao ensino das áreas Afins ao Turismo, que chegou em 2008 com 374 cursos (vide Quadro 8).

O ensino do Turismo em 2007 apresentou uma oferta de 526 cursos, enquanto o ensino das Áreas Afins ao Turismo no ano de 2008 chegou a 374 cursos. Ao atingir essa oferta de cursos, o mercado começou a sofrer retração de demanda, isto é, nos anos seguintes iniciou-se a diminuição no número de cursos existentes no país, devido à falta de ingressos de alunos. Em 2009 existiam 344 cursos de Turismo e 313 cursos das Áreas Afins ao Turismo em funcionamento (vide Quadro 3 e Quadro 8) e 10 cursos de Educação a Distancia de Turismo e das Áreas Afins ao Turismo, o que totalizou 667 cursos destinados à formação de profissionais para a área de Turismo.

De acordo com as informações constantes no Quadro 5 pode-se constatar que o ensino do Turismo está passando por um período de instabilidade, isto é, em 2004 ofereceu o maior número de vagas (59.137) e também teve o maior número de candidatos inscritos no vestibular (81.995). Já a partir do ano seguinte as suas ofertas de vagas, número de candidatos inscritos e número de ingressos começaram a decrescer, apresentando índices negativos de variação anual, exceto candidatos inscritos em 2008 , que apresentou índice positivo de $0,2 \%$.

No caso do Turismo outro agravante que provocou a sua instabilidade foi o surgimento dos cursos das Áreas Afins ao Turismo, originados a partir de disciplinas da matriz curricular do curso de Turismo. Por exemplo, muitas pessoas que poderiam cursar Turismo para se qualificar em Eventos e/ou em Transportes, passaram a ter a opção de fazer cursos específicos dessas áreas do conhecimento. Supõe-se que isso tenha provocado a diminuição da demanda pelos cursos de Turismo.

Paralelamente ao ensino do Turismo os cursos das Áreas Afins ao Turismo têm mostrado crescimento ano a ano, até porque são cursos novos que ainda estão se 
firmando no mercado, mas em 2002 e 2007 já apresentaram índices negativos de candidatos inscritos em relação às vagas oferecidas, e em 2009 o número de ingressos apresentou queda de $-3,4 \%$.

A seguir o Quadro 13 mostra um comparativo do ensino do Turismo e das Áreas Afins ao Turismo, onde se percebe algumas semelhanças e também diferenças que marcam o seu comportamento no mercado, nesse quadro não foram inseridos os cursos de Educação a Distancia, devido à escassez de dados para realizar um estudo comparativo.

\begin{tabular}{|c|c|c|}
\hline Período & Curso de Turismo & Áreas Afins ao Turismo \\
\hline $\begin{array}{ll}1995 \quad \mathrm{a} \\
2008\end{array}$ & Cresceu número de cursos até 2007. & Cresceu número de cursos até 2008 \\
\hline $\begin{array}{l}1995 \\
2008\end{array}$ & $\begin{array}{l}\text { O número de vagas oferecidas no período apresentou } \\
\text { crescimento oscilante, variando de } 76,9 \% \text { a } 5,8 \% \text {, } \\
\text { atingindo índices negativos nos anos de } 2005,2007 \text {, } \\
2008 \text { e } 2009 \text {; } \\
\text { O número de candidatos inscritos no vestibular } \\
\text { mostrou crescimento até o ano de } 2004 \text {, a partir de } \\
2005 \text { até } 2007 \text { apresentou índices negativos de } \\
\text { crescimento. Em } 2008 \text { teve um crescimento quase } \\
\text { inexpressivo de } 0,2 \% \text {. }\end{array}$ & $\begin{array}{l}\text { O número de vagas oferecidas no período apresentou } \\
\text { crescimento oscilante, variando de } 211,8 \% \text { a } 4,7 \% \text {; } \\
\text { O número de ingressos aumentou de forma moderada, } \\
\text { uma média de } 10 \% \text { ao ano. }\end{array}$ \\
\hline 2002 & Maior número de ingressos. & $\begin{array}{l}\text { O número de candidatos inscritos apresentou índice de - } \\
4,8 \% \text { de crescimento. }\end{array}$ \\
\hline $\begin{array}{ll}2003 \\
2008\end{array}$ & $\begin{array}{l}\text { Os percentuais de vagas não preenchidas } \\
\text { ultrapassaram a casa dos } 50 \% \text {, chegando a } 79,0 \% \text { em } \\
2009 ; \\
\text { Diminuição do número de ingressos. }\end{array}$ & $\begin{array}{l}\text { O percentual de vagas não preenchidas manteve-se } \\
\text { acima de } 50 \% \text {, chegando em } 2009 \text { a } 63,1 \% \text {. }\end{array}$ \\
\hline 2004 & $\begin{array}{l}\text { Apresentou a maior oferta de vagas (59.137) e } \\
\text { também o maior número de candidatos inscritos no } \\
\text { vestibular (81.995). }\end{array}$ & $\begin{array}{l}\text { Maior taxa de vagas não preenchidas verificada no } \\
\text { período de } 1995 \text { a } 2004(57,0 \%) \text {. }\end{array}$ \\
\hline $\begin{array}{l}2005 \\
2008\end{array}$ & $\begin{array}{l}\text { As taxas de variação de oferta de vaga, candidatos } \\
\text { inscritos e número de ingressos, todas apresentaram } \\
\text { índices negativos, exceto candidatos inscritos em } \\
2008 \text {, que apresentou índice positivo de } 0,2 \% \text {. }\end{array}$ & $\begin{array}{l}\text { Diminuição das taxas de vagas não preenchidas entre } \\
2005 \text { e } 2007 \text {. }\end{array}$ \\
\hline 2007 & $\begin{array}{l}\text { O número de candidatos inscritos apresentou índice } \\
\text { negativo de }-13,4 \% \text {. }\end{array}$ & $\begin{array}{l}\text { O número de candidatos inscritos apresentou índice de - } \\
4,0 \% \text { de crescimento. }\end{array}$ \\
\hline 2008 & $\begin{array}{l}\text { Taxa de vagas não preenchidas }(75,5 \%) \\
\text { Variação da taxa de candidatos inscritos foi de } 0,2 \% \text {. }\end{array}$ & $\begin{array}{l}\text { Aumento oferta de vagas em } 34,2 \% \text {; } \\
\text { Aumento do número de candidatos inscritos em } 37,6 \% \text {; } \\
\text { Aumento do número de ingressos em } 28,6 \% \text {; } \\
\text { Aumento taxa de vagas não preenchidas em } 58,6 \% \text {. }\end{array}$ \\
\hline 2009 & $\begin{array}{l}\text { Aumento da taxa de vagas não preenchidas }(79,0 \%) \text {; } \\
\text { A taxa de candidatos inscritos apresentou variação de } \\
-40,3 \% \text { com queda bastante considerável em relação } \\
\text { ao ano anterior. }\end{array}$ & $\begin{array}{l}\text { Número de Ingressos apresentou índice negativo (- } \\
3,4 \%) \text {; } \\
\text { Aumento taxa de vagas não preenchidas }(63,1 \%) \text {; } \\
\text { O número de candidatos inscritos aumentou } 67,0 \% \text {. }\end{array}$ \\
\hline
\end{tabular}

QUADRO 13 - COMPARATIVO DO ENSINO DO TURISMO E DAS ÁREAS AFINS AO TURISMO NO PERÍODO DE 1995 A 2008.

QUADRO ELABORADO POR: MARLENE MATIAS.

Nota: (-) Dado não disponível.

Mesmo não considerando os cursos de Educação a Distância no Quadro 13, porque eles se referem somente ao ano de 2009, percebe-se que esses cursos exercem 
concorrência para os cursos de Turismo e também para os cursos das Áreas Afins ao Turismo, porque eles poderão atingir um número maior de candidatos, devido a não exigência presencial para a realização dos estudos.

\section{4 - REFERÊNCIAS}

ANSARAH, M. G. dos R.; REJOWSKI, M. Panorama do ensino em Turismo no Brasil, Graduação e Pós-graduação. In: Turismo e Análise. São Paulo: ECA/USP, v. 7, n. 1, maio 1996.

BRASIL. MTUR/EMBRATUR - Ministério do Turismo/Instituto Brasileiro de Turismo. Atualização das Instituições de Ensino Superior que possuem Curso de Turismo. Brasília, 2010 (mimeo.).

MTUR/EMBRATUR - Ministério do Turismo/Instituto Brasileiro de Turismo. Anuário Estatístico 2011. Brasília, 2011.

BRASIL. MEC/INEP/DEED - Ministério da Educação/Instituto Nacional de Pesquisas Educacionais Anísio Teixeira/Diretoria de estatísticas Educacionais. Sinopse Estatística e Microdados do Censo da Educação Superior de 1995 a 2009. Disponível em: <http://www.inep.gov.br/superior/censosuperior/default.asp>. Acesso em: $31 / 05 / 2010$.

PEÑA, M. de Los D. Educação a Distancia panorama 2010. Disponível em: <http://www.slideshare.net/mariloli/educao-a-distancia-no-brasil-7414198>. Acesso em: 20/08/2011.

REJOWSKI, M. Turismo e Pesquisa Científica: pensamento Internacional x Situação Brasileira. Campinas/SP: Papirus, 1996.

TRIGO, L. G. de G. Cronologia do Turismo no Brasil. São Paulo: CTI/Terra, 1991.

Viagem na Memória: Guia Histórico das Viagens e do Turismo no Brasil. São Paulo: Senac, 2000.

Recebido em: 11-09-2011.

Aprovado em: 11-10-2011. 